\title{
Following up users of a pharmacy-based screening and brief intervention service
}

\author{
Janet Krska ${ }^{1 *}$, Elizabeth Stokes ${ }^{2}$, Adam Mackridge $^{2}$ \\ From International Network on Brief Interventions for Alcohol and Other Drugs (INEBRIA) Meeting 2013 \\ Rome, Italy. 18-20 September 2013
}

Pharmacy-based alcohol screening and brief intervention (SBI) services in England vary in follow-up requirements and achieving follow-up can be challenging. Little is known about service-user views and this study aimed to explore these as well as the feasibility of follow-up. The study was funded by Liverpool Primary Care Trust using an unrestricted educational grant from Lundbeck Limited. Five pharmacies providing alcohol SBI services were purposively selected across three areas. Forty individuals receiving SBI interventions were invited by pharmacy staff to participate and contact details recorded with consent. A researcher conducted semi-structured telephone interviews at 1-2 weeks and 3 months after service use. Interview 1 covered views on the service and interview 2 covered behaviour changes, including subsequent discussions with third parties. Institutional ethics approval was obtained.

Sixteen service users took part in the first follow-up (40\%); all viewed it positively and 'a good idea', although one felt services should be targeted to under-50s. Not all regarded it as personally relevant and one admitted dishonesty in his responses. However, all felt at ease having a discussion in the consultation room about drinking. Fourteen of the 16 (86\%) agreed to three-month followup. Of these, six reported talking to others about their own drinking habits and three had discussed the service with family and friends, of whom two had recommended they should make use of it. Two had made significant changes to lifestyle that they attributed to the pharmacy intervention. Pharmacy alcohol services were well received by service users interviewed, a significant proportion of whom had subsequently discussed the pharmacy interaction and/or alcohol use with other people,

\footnotetext{
* Correspondence: j.krska@kent.ac.uk

${ }^{1}$ Medway School of Pharmacy, Universities of Greenwich and Kent, Chatham Maritime, Kent, UK

Full list of author information is available at the end of the article
}

potentially leading to a cascade effect. Two of 16 interviewees reported significant lifestyle changes at 3 months, which tallies with findings from services based elsewhere. Good follow-up rates were achieved at 2 weeks and three months.

\section{Authors' details}

${ }^{1}$ Medway School of Pharmacy, Universities of Greenwich and Kent, Chatham Maritime, Kent, UK. ${ }^{2}$ School of Pharmacy and Biomolecular Sciences, Liverpool John Moores University, Liverpool, UK.

Published: 4 September 2013

\section{doi:10.1186/1940-0640-8-S1-A41}

Cite this article as: Krska et al:: Following up users of a pharmacy-based screening and brief intervention service. Addiction Science \& Clinical Practice 2013 8(Suppl 1):A41.

\section{Submit your next manuscript to BioMed Central and take full advantage of: \\ - Convenient online submission \\ - Thorough peer review \\ - No space constraints or color figure charges \\ - Immediate publication on acceptance \\ - Inclusion in PubMed, CAS, Scopus and Google Scholar \\ - Research which is freely available for redistribution

C Biomed Central

() 2013 Krska et al; licensee BioMed Central Ltd. This is an Open Access article distributed under the terms of the Creative Commons Attribution License (http://creativecommons.org/licenses/by/2.0), which permits unrestricted use, distribution, and reproduction in any medium, provided the original work is properly cited. 